\title{
Advancing the science of patient decision aids through reporting guidelines
}

\author{
Robert J Volk, ${ }^{1}$ Angela Coulter ${ }^{2}$
}

'Department of Health Services Research, Division of Cancer Prevention \& Population Sciences, The University of Texas MD Anderson Cancer Center, Houston, Texas, USA ${ }^{2}$ Health Services Research Unit, Nuffield Department of Population Health, University of Oxford, Oxford, Oxfordshire, UK

\section{Correspondence to} Professor Robert J Volk Department of Health Services Research, The University of Texas MD Anderson Cancer Center, Houston, TX 77030, USA bvolk@mdanderson.org

Accepted 4 January 2018 Published Online First 25 January 2018

\section{SLinked}

- http://dx.doi.org/10.1136/ bmjqs-2017-006986

- http://dx.doi.org/10.1136/ bmjqs-2017-007019

- http://dx.doi.org/10.1136/ bmjqs-2017-006985

Check for updates

To cite: Volk RJ, Coulter A. BMJ Qual Saf

2018:27:337-339.
Patient decision aids (PDAs) are tools designed to help people make deliberative choices about their healthcare options using the best available evidence. They provide balanced information about treatment choices and help patients construct, clarify and communicate what is important to them in making healthcare choices. PDAs can prepare patients to make informed, values-based decisions with their healthcare providers. ${ }^{1-3}$ The evidence base on PDAs has grown rapidly over the past two decades. The most recent update to the Cochrane systematic review of PDAs included 105 randomised controlled trials published through April $2015 .^{2}$ This number excludes trials comparing complex to simpler PDAs and other evaluations of PDAs using non-randomised designs. People who use decision aids improve their knowledge of the options, report feeling clearer and better informed about the options, have more accurate expectations about benefits and harms of options, and participate more in decision-making compared with people who don't use decision aids. ${ }^{2}$

Founded in 2003, the International Patient Decision Aid Standards (IPDAS) Collaboration is a multidisciplinary group of researchers, clinicians and other stakeholders from around the world who share an interest in the development and use of PDAs. A description of the IPDAS history, its membership and activities can be found at the IPDAS website (http://ipdas.ohri.ca/). It is a voluntary organisation that receives no centralised financial support for its efforts. The Collaboration was established in response to concerns about the rapid increase in the number of PDAs of unknown quality that were being developed by different individuals and groups around the world. The Collaboration prioritised the need for a set of standard criteria to guide the quality appraisal of PDAs. The purpose of IPDAS is to enhance the quality and effectiveness of PDAs by establishing a common evidence framework for the content, development, implementation and evaluation of PDAs.

The Collaboration's initial task was development of a checklist of internationally approved criteria to determine the quality of PDAs (see table 1). Twelve quality dimensions were identified and workgroups conducted extensive evidence reviews, resulting in a series of background documents (http://ipdas. ohri.ca/resources.html). These documents were then used as the evidence sources in a modified Delphi consensus voting process involving $>100$ stakeholders from 12 countries to select a final set of criteria for the checklist. ${ }^{4}$ The final IPDAS Checklist includes 74 criteria, and a shorter version is used to report the quality of aids included in the Ottawa $\mathrm{A}$ to $\mathrm{Z}$ Decision Aid Inventory (https://decisionaid.ohri.ca/cochinvent. php). A second initiative was undertaken to provide a more precise, quantitative measure of a decision aid's quality. The IPDAS instrument (or IPDASi) includes 10 dimensions with 47 items, and a shorter, 19 -item version is available. ${ }^{5}$

As the importance of certifying PDAs was recognised, the IPDAS Collaboration undertook a third initiative to identify a minimum set of standards that could be used to certify the quality of PDAs. A modified Delphi process involving $>100$ individuals with experience in decision aids from 16 countries was used to rate each criterion from the IPDASi on the basis of the potential for harmful bias in a patient's decision-making if the criterion were not present or of low quality in a decision aid. From there, criteria 
Table 1 Achievements of the International Patient Decision Aid Standards (IPDAS) Collaboration

\begin{tabular}{|c|c|c|}
\hline & Product & Description \\
\hline $2003-2006$ & IPDAS Checklist & $\begin{array}{l}\text { Internationally approved criteria for determining the quality of patient } \\
\text { decision aids }\end{array}$ \\
\hline $2006-2009$ & IPDASi Instrument & Instrument for rating the quality of patient decision aids \\
\hline 2009-2013 & IPDAS Minimum Standards & $\begin{array}{l}\text { An abbreviated set of essential criteria for certification of patient decision } \\
\text { aids }\end{array}$ \\
\hline $2011-2013$ & Updated evidence underlying the IPDAS Checklist & $\begin{array}{l}\text { Update on the conceptual and theoretical evidence underlying the } 12 \\
\text { dimensions for addressing the quality of patient decision aids }\end{array}$ \\
\hline 2014-2017 & SUNDAE Checklist & Reporting standards for patient decision aid evaluation studies \\
\hline
\end{tabular}

Adapted with permission from D Stacey (see http://ipdas.ohri.ca/resources.html for additional details).

SUNDAE, Standards for UNiversal reporting of patient Decision Aid Evaluations.

were grouped into three broad categories: qualifying criteria, essential for a tool to be considered a PDA (6 items); certification criteria, necessary for an aid to be certified (6 items plus 4 specific to aids about screening); and quality criteria, including items not essential for reducing harms (28 items). ${ }^{6}$ Recognising how rapidly the evidence base informing the IPDAS Checklist was evolving, the Collaboration conducted an extensive update of the empirical and theoretical evidence from each of the 12 original quality dimensions. As has been the history of IPDAS, 102 individuals from 10 countries volunteered to participate in the updating effort and authored the updated background documents. ${ }^{7}$

Standards developed by IPDAS are now being used to support the development, certification and adoption of high-quality PDAs across the globe. In the USA, certification of PDAs has gained momentum both at the state and national level. Washington State has passed legislation that encourages shared decision-making conversations supported by the use of certified PDAs. ${ }^{8}$ Building from the IPDAS experience, Washington's Health Care Authority launched a process for certifying PDAs in 2016. The National Quality Forum, a non-profit organisation that provides standards for measuring healthcare quality, relied on the Washington Health Care Authority experience and expertise of the IPDAS Collaboration in developing the document National Standards for the Certification of Patient Decision Aids with the goal of supporting a national certification effort (http://www.qualityforum.org). While no other country has yet developed a formal certification scheme for PDAs, IPDAS criteria have influenced the development and evaluation of these tools around the world. The Ottawa inventory includes decision aids from 10 countries (Australia, Canada, Finland, Germany, Hong Kong, Italy, the Netherlands, Saudi Arabia, Sri Lanka, the UK, the USA), and a recent overview of international developments in shared decision-making in 22 countries added five more countries where IPDAS has been influential (Denmark, Malaysia, Norway, Switzerland and Taiwan). ${ }^{9}$

In this issue of BMJ Quality \& Safety, Sepucha and colleagues present the most recent products of the IPDAS
Collaboration: new standards for reporting of PDA evaluation studies and a checklist for authors and journal editors. ${ }^{11} 11$ This international group of decision science researchers drew its members from the larger IPDAS Collaboration. Highlighting significant gaps in published PDA evaluations, the IPDAS reporting guidelines workgroup (IPDAS-RG) undertook a rigorous, multiphased, iterative development process adapted from Enhancing the QUAlity and Transparency Of Health Research in producing the new Standards for UNiversal reporting of patient Decision Aid Evaluations (SUNDAE) Checklist. Focusing on the 12 IPDAS quality dimensions and other reporting guidelines, the IPDAS-RG completed a comprehensive needs assessment and drafted an initial set of items for the checklist. A consensus process followed, where items were reviewed during a workshop at the 2015 ISDM conference followed by a two-stage Delphi process involving an international group of researchers, developers, clinicians, patient/consumer advocates, journal editors and guideline developers. The 26-item SUNDAE Checklist should greatly enhance the transparency and completeness of reporting PDA evaluations.

Why do reporting standards matter? Clear and consistent reporting of study methods and results will improve our understanding of the role of theory in impacting patient outcomes, allow for synthesis of findings from multiple studies addressing specific decision contexts, types of aids or patient populations, and support replication, to name a few reasons. The use of reporting standards should improve the quality of the evidence about the implementation and effectiveness needed to inform and modify certification criteria for PDAs. Implementation of PDAs remains a significant challenge. A better understanding of how aids are implemented in published evaluations, including when decision support was provided within the work flow (delivery channels), who delivered the aid, what format was used and how fidelity was assessed, is essential to improve insights into the best use of PDAs. An example is the quality improvement project by Mangla et $a l,{ }^{12}$ which also appears in this issue of BMJ Quality \& Safety reporting on a three-phased strategy for promoting the delivery of PDAs for hip and knee osteoarthritis, 
lumbar herniated disc and lumbar spinal stenosis. ${ }^{11}$ These authors followed the Standards for Quality Improvement Reporting Excellence Guidelines ${ }^{13} 14$ for quality improvement reports and provide a rich understanding of the methods used to deliver the aids.

Addressing conflicts of interest in publications about PDA evaluations will be particularly challenging for authors and journals. Authors are expected to disclose any interest in the options included in the aid or a financial interest in the decision aid itself. The SUNDAE developers appropriately define a spectrum of conflicts, including the following: professional interests, where the specialty of an author may have an interest in the choices a patient makes; financial interests, when the author may benefit from the sale or use of an aid, or from the options included in an aid; and intellectual interests, such as benefiting academically or intellectually by intangible personal gain. With many groups now producing PDAs, transparency is essential and we must be vigilant in ensuring the full range of conflicts are addressed in any published evaluations.

We encourage authors to include the SUNDAE Checklist with manuscripts they submit for publication when they report on evaluations of PDAs. There are also practical considerations in addressing the full checklist in a single publication. The IPDAS-RG members note that authors may choose to reference other publications or supplementary materials. To address this concern, we suggest that source documents become a best practice for decision aid developers and accompany release of PDAs.

The rapidly increasing pace of decision aid development means that formal evaluation and publication in academic journals will likely apply to only a minority of tools in future. However, we believe the SUNDAE guidelines should be observed by all decision aid developers. If PDAs are to move from the periphery into mainstream care, they must gain the trust of clinicians and patients. To achieve this, developers should provide clear information about their processes, making it available on websites or on request. The SUNDAE Checklist shows them how this can be done.

Contributors Both authors contributed to the conception of the paper, critically read and modified subsequent drafts, and approved the final version.

Funding This work was partially supported by a grant from The University of Texas MD Anderson Cancer Center Duncan Family Institute for Cancer Prevention and Risk Assessment (RJV).

Competing interests $\mathrm{RJV}$ and $\mathrm{AC}$ are members of the Steering Committee of the International Patient Decision Aid Standards Collaboration. From 1999 to 2016, AC undertook paid consultancy for the not-for-profit Informed Medical Decisions Foundation of Boston, USA, which carried out research and development on shared decision-making and patient decision aids.
Provenance and peer review Commissioned; internally peer reviewed.

(C) Article author(s) (or their employer(s) unless otherwise stated in the text of the article) 2018. All rights reserved. No commercial use is permitted unless otherwise expressly granted.

\section{REFERENCES}

1 O'Connor A, Llewellyn-Thomas H, Stacey D, eds. IPDAS collaboration background document, 2005. http://ipdas.ohri. ca/IPDAS_Background.pdf (accessed 27 Dec 2017).

2 Stacey D, Légaré F, Lewis K, et al. Decision aids for people facing health treatment or screening decisions. Cochrane Database Syst Rev 2017;4:CD001431.

3 Elwyn G, Frosch D, Volandes AE, et al. Investing in deliberation: a definition and classification of decision support interventions for people facing difficult health decisions. Med Decis Making 2010;30:701-11.

4 Elwyn G, O'Connor A, Stacey D, et al. Developing a quality criteria framework for patient decision aids: online international Delphi consensus process. BMJ 2006;333:417.

5 Elwyn G, O'Connor AM, Bennett C, et al. Assessing the quality of decision support technologies using the International Patient Decision Aid Standards instrument (IPDASi). PLoS One 2009;4:e4705.

6 Joseph-Williams N, Newcombe R, Politi M, et al. Toward minimum standards for certifying patient decision aids: a modified delphi consensus process. Med Decis Making 2014;34.

7 Volk RJ, Llewellyn-Thomas H, Stacey D, et al. Ten years of the International Patient Decision Aid Standards Collaboration: evolution of the core dimensions for assessing the quality of patient decision aids. BMC Med Inform Decis Mak 2013;13(Suppl 2):S1.

8 Spatz ES, Elwyn G, Moulton BW, et al. Shared decision making as part of value based care: New U.S. policies challenge our readiness. Z Evid Fortbild Qual Gesundhwes 2017;123-124:104-8.

9 Härter M, Moumjid N, Cornuz J, et al. Shared decision making in 2017: International accomplishments in policy, research and implementation. Z Evid Fortbild Qual Gesundhwes 2017;123-124:1-5.

10 Sepucha KR, Abhyankar P, Hoffman AS, et al. Standards for UNiversal reporting of patient Decision Aid Evaluation studies: the development of SUNDAE Checklist. BMJ Qual Saf 2018;27:380-8.

11 Hoffman AS, Sepucha KR, Abhyankar P, et al. Explanation and elaboration of the Standards for UNiversal reporting of patient Decision Aid Evaluations (SUNDAE) guidelines: examples of reporting SUNDAE items from patient decision aid evaluation literature. BMJ Qual Saf 2018;27:389-412.

12 Mangla M, Cha TD, Dorrwachter JM, et al. Increasing the use of patient decision aids in orthopaedic care: results of a quality improvement project. BMJ Qual Saf 2018;27:347-54.

13 Ogrinc G, Davies L, Goodman D, et al. SQUIRE 2.0 (Standards for QUality Improvement Reporting Excellence): revised publication guidelines from a detailed consensus process. BMJ Qual Saf 2016;25:986-92.

14 Goodman D, Ogrinc G, Davies L, et al. Explanation and elaboration of the SQUIRE (Standards for Quality Improvement Reporting Excellence) Guidelines, V.2.0: examples of SQUIRE elements in the healthcare improvement literature. BMJ Qual Saf 2016;25:e7. 